Acta Crystallographica Section D

Biological

addenda and errata

Crystallography

ISSN 0907-4449

\title{
Metal-ligand geometry relevant to proteins and in proteins: sodium and potassium. Corrigendum
}

\author{
Marjorie M. Harding \\ Institute of Structural and Molecular Biology, University of Edinburgh, Michael \\ Swann Building, Edinburgh EH9 3JR, Scotland \\ Correspondence e-mail: marjorie.harding@ed.ac.uk
}

The article by Harding [(2002) Acta Cryst. D58, 872-874] is corrected.

In the first sentence of $\S 4$, Conclusions, of the article by Harding (2002) two numbers were accidentally interchanged. The sentence should start 'Target distances for $\mathrm{K}^{+} \ldots \mathrm{O}$ and $\mathrm{Na}^{+} \ldots \mathrm{O}$ can be set (usually 2.84 and $2.42 \AA$, respectively; see Table $2 a$ ) for use as restraints or in validation...'. I am grateful to Professor Peter Artymiuk for pointing this out.

\section{References}

Harding, M. M. (2002). Acta Cryst. D58, 872-874. 